\title{
Prognostic factors and outcome of Post-Neonatal Tetanus in an intensive care unit of a Tertiary Care Hospital
}

\author{
Nighat Sultana ${ }^{1}$, Attia Bari², \\ Mehwish Faizan ${ }^{3}$, Muhammad Sarwar ${ }^{4}$
}

\begin{abstract}
Objective: To determine the prognostic factors and outcome of tetanus in children of post-neonatal age admitted in the intensive care unit (ICU) of a tertiary care hospital.

Methods: This prospective cross sectional study, carried out in the Pediatric ICU of The Children's Hospital Lahore from Jan 2013 to March 2017. Children of both genders with age range of two months to 16 years diagnosed clinically as tetanus were included. All 132 patients were scrutinized for all possible risk factors, need for mechanical ventilation and outcome. Data was analyzed by SPSS version 20.

Results: Mean age of children was $7.5 \pm 3.4$ years with male predominance $(70.5 \%)$. Only $(38.6 \%)$ received three doses of vaccination but none had booster dose. Trauma (43.2\%) encompassed maximum predisposing factor followed by ear or nose prick and ear discharge. Mean duration of ICU stay was $20 \pm 13.3$ days. Mortality rate was $(17.4 \%)$. Ventilator support was given to $(78.8 \%)$. Neurological outcome was normal in (82.6\%). Trauma, ear or nose prick in girls and ear discharge were significantly associated with poor outcome and death with $\mathrm{p}$-value of $<0.001,0.011$ and $<0.001$ respectively. Other factors associated with poor outcome were need for mechanical ventilation and neurological impairment with $p$-value of 0.001 and $<0.001$ respectively.

Conclusion: Tetanus is causing our children to suffer from devastating disease. Vaccination status is not satisfactory and along with trauma, ear discharge and ear or nose prick are identifiable risk factors. To combat these issues large scale vaccination and booster doses remains promising option.
\end{abstract}

KEYWORDS: Tetanus, Autonomic instability, Children, Neurological, Outcome, Ventilation.

doi: https://doi.org/10.12669/pjms.35.5.656

How to cite this:

Sultana N, Bari A, Faizan M, Sarwar M. Prognostic factors and outcome of Post-Neonatal Tetanus in an intensive care unit of a Tertiary Care Hospital. Pak J Med Sci. 2019;35(5):1233-1237. doi: https://doi.org/10.12669/pjms.35.5.656

This is an Open Access article distributed under the terms of the Creative Commons Attribution License (http://creativecommons.org/licenses/by/3.0), which permits unrestricted use, distribution, and reproduction in any medium, provided the original work is properly cited.

1. Dr. Nighat Sultana, MCPS, FCPS.

Department of Pediatric ICU,

2. Dr. Attia Bari, DCH, MCPS, FCPS, MHPE.

Department of Pediatric,

3. Dr. Mehwish Faizan, FCPS.

Department of Pediatric,

4. Dr. Muhammad Sarwar, MCPS, FCPS.

Department of Pediatric ICU,

1-4: The Children's Hospital and The ICH,

Lahore, Pakistan.

Correspondence:

Dr. Attia Bari,

The Children's Hospital \& The Institute of Child Health,

Lahore, Pakistan.

Email: drattiabari@gmail.com

* Received for Publication:

March 2, 2019

* Revision Received:

* Revision Accepted:
June 15, 2019

June 20, 2019

\section{INTRODUCTION}

Tetanus is a vaccine preventable disease but even in this era of effective vaccines against most preventable diseases tetanus is still considered a common public health problem particularly in developing countries causing huge morbidity and mortality. However, in resource rich countries with the help of a good immunization coverage the disease incidence is decreased with very low mortality rates. ${ }^{1}$

Tetanus is caused by a potent exotoxin called tetanospasmin produced by gram positive organism Clostridium tetani. ${ }^{2}$ Tetanus is the only vaccinepreventable disease which is not communicable and is acquired through environmental exposure to the spores of Clostridium tetani. ${ }^{3}$ It is an acute 
neuromuscular disorder diagnosed clinically and is characterized by increased muscle tone, rigidity and spasms caused by neurotoxin. There may be autonomic dysfunction and in severe forms patients with tetanus requires respiratory and hemodynamic support. ${ }^{4}$

In most cases of tetanus an acute penetrating injury is the preceding event but sometimes the injury is so mild and it often go unnoticed without seeking medical treatment. The other factors which may be associated with tetanus are chronic skin ulcers, burns, surgery, abscesses, gangrene, ear discharge and ear or nose pricks using unhygienic needles. The portal of entry of clostridium tetani is not identifiable in all cases. ${ }^{5}$

The main reason for developing this deadly disease is low immunization coverage and deficient booster doses of tetanus toxoid at appropriate period in the immunization schedule contributing to the high disease burden in developing countries. There are many other factors involved in this disease including lifestyle, social influence and living conditions particularly in rural areas and in warm climates. ${ }^{6}$

In our experience, substantial number of tetanus cases are admitted with severe disease. There are number of studies regarding risk factors available with very few studies from Pakistan particularly documenting admission and monitoring in Intensive care unit (ICU) setting and outcome of children with severe tetanus. There is a need and room to document our experience about this aspect. Hence, we planned this study to analyze clinical

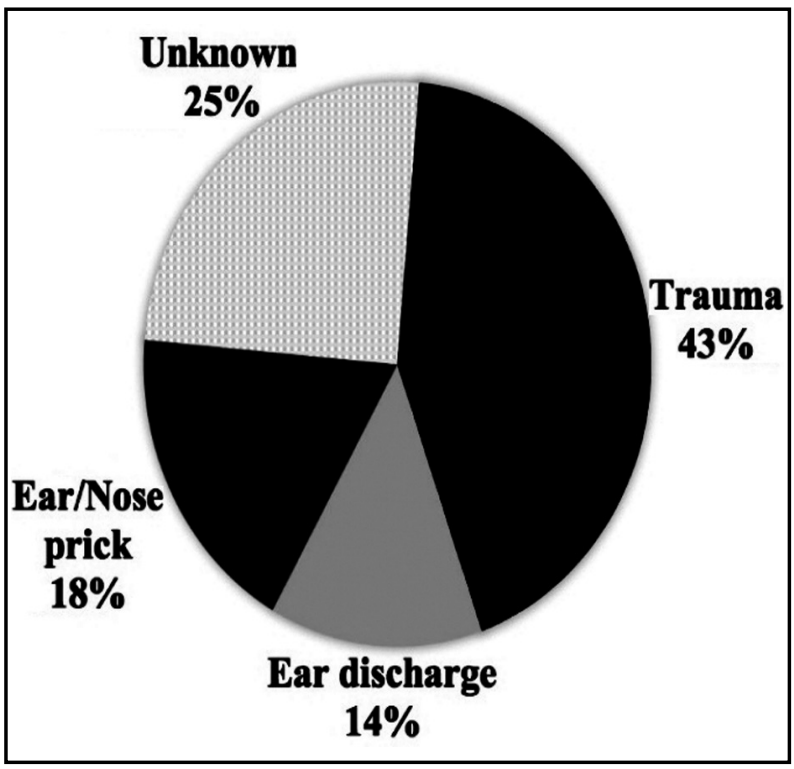

Fig.1: Portal of entry in post neonatal tetanus. characteristics, prognostic factors and outcome of post-neonatal tetanus cases admitted to ICU of our tertiary care center.

\section{METHODS}

This was a prospective cross sectional study, carried out in Pediatric ICU of The Children's Hospital \& The Institute of Child Health (ICH), from Jan 2013 to March 2017 after the approval from Institutional Review Board. We used a Questionnaire Performa for data collection and before data collection informed written consent from parents was taken. As the exact prevalence of post neonatal tetanus in the developing countries is not known so the sample size was calculated to be 132 by taking $8-15 \%$ deaths in children due to tetanus. Non-probability convenience sampling method was used. Children of both gender with age range of two months to 16 years who were diagnosed as tetanus on the clinical basis including tetanic spasms, locked jaw and clear conscious level were included. While patients less than two months and having seizures due to any other disease or past history of neurological disease were excluded from the study.

In all included patients age, sex, duration of illness, presenting symptoms were documented and all 132 patients were scrutinized for possible risk factors, need for mechanical ventilation, post ventilation neurological status and outcome in the form of discharged, died, left against medical advice (LAMA) and transferred out of ICU to a medical ward after stabilization and discharged.

Statistical analysis: Data was analyzed by SPSS version 20. Descriptive statistics were used to describe the demographic details as mean and percentages. Statistical analysis was performed using chi-square test to see association between outcome and age group, duration of illness and ventilation requirement. A p-value of less than 0.05 was considered significant.

\section{RESULTS}

The results of our study showed predominance of males $93(70.5 \%)$ over females $39(29.5 \%)$. Mean age of children was $7.5 \pm 3.4$ years. Major proportion of patients were in the age range of 5.1-10 years constituting $60(45.5 \%)$ of total patient, while 40 $(30.3 \%)$ cases were in age group less than 5 years. Majority belonged to urban areas 101 (70.5\%). Only $51(38.6 \%)$ received three doses of tetanus toxoid but none had any booster dose (Table-I). 
Table-I: Demographics of study population.

\begin{tabular}{lcc}
\hline Characteristics & Frequency $(n)$ & Percentage \\
\hline Age & & \\
$1-5$ Years & 40 & 30.3 \\
5.1-10 Years & 60 & 45.5 \\
10.1-14 Years & 32 & 24.2 \\
Sex & & \\
Male & 93 & 70.5 \\
female & 39 & 29.5 \\
Address & & \\
Rural & 101 & 76.5 \\
Urban & 31 & 23.5 \\
Vaccination status & & \\
1 dose & 38 & 28.8 \\
2 doses & 43 & 32.6 \\
3 doses & 51 & 38.6 \\
Booster dose & 0 & 0 \\
\hline
\end{tabular}

Definite history of trauma was positive in 57 $(43.2 \%)$ patients. Other predisposing factors shown in (Fig.1).

Mean duration of symptoms was $8.3 \pm 3.2$ days. Mean duration of ICU stay was $20 \pm 13.3$ days. Out of 132 patients $104(78.8 \%)$ patients required mechanical ventilation due to intractable seizures and respiratory compromise. In these 104 patients $25(19 \%)$ who had difficulty in weaning from ventilation required tracheostomy. Mean duration of mechanical ventilation was $18 \pm 10.5$ days. A significant proportion had autonomic instability 75(56.8\%). Nosocomial infection occurred in 97(73.5\%). Majority had normal neurological outcome $109(82.6 \%)$. In our study mortality rate was $17.4 \%$, maximally involving children 5.1-10 years $(20 \%)$. Seventeen $(12.9 \%)$ patients left against medical advice due to critical condition (Table-II).

Trauma, ear or nose prick in girls and ear discharge were significantly associated with poor outcome and death with $\mathrm{p}$-value of $<0.001,0.012$ and $<0.001$ respectively while we could not establish significant association of nosocomial infection with outcome
Table-II: Factors and Outcome of patients with Tetanus during ICU Stay.

\begin{tabular}{lcc}
\hline Factors E Outcome & $\begin{array}{c}\text { Frequency } \\
(n)\end{array}$ & $\begin{array}{c}\text { Percentage } \\
(\%)\end{array}$ \\
\hline Need for Mechanical & 104 & 79 \\
Ventilation & 25 & 19 \\
Tracheostomy & 25 & 19 \\
MgSo $_{4}$ & 75 & 57 \\
Autonomic instability & 97 & 74 \\
Nosocomial infection & 109 & 83 \\
Normal neurological & & \\
outcome & & \\
Outcome & 16 & 13.6 \\
$\quad$ Discharged & 23 & 17.4 \\
Died & 17 & 12.9 \\
LAMA & 74 & 56.1 \\
Shifted to medical ward & & \\
$\quad$ after stabilization & & \\
\hline
\end{tabular}

p-value 0.053. Other factors associated with poor outcome were patients with intractable seizures requiring $\mathrm{MgSO}_{4^{\prime}}$, need for mechanical ventilation and neurological impairment with prolonged ventilation and brain anoxia with p-value of 0.003 , 0.001 and $<0.001$ respectively (Table-III).

\section{DISCUSSION}

Tetanus is a serious illness and often a lifethreatening disease. The relative incidence of tetanus is higher in neonatal age group due to improper sterilization but tetanus is still seen in older age group in under developed countries with inadequate vaccination coverage. In our study the children were in post neonatal age and we found that mean age of presentation was $7.5 \pm 3.4$ years consistent with 8 years in a study from Ethiopia and a study by Alhaji et al. showing mean age of $6.9 \pm 3.87$ years. ${ }^{2,7}$ Our study revealed that brunt of burden is born by age group of 5-10 years with $45.5 \%$ cases followed by $<5$ years $(30.3 \%)$. This

Table-III: Factors affecting outcome of patient with Tetanus in intensive care unit.

\begin{tabular}{lccccc}
\hline \multirow{2}{*}{ Variables } & \multicolumn{5}{c}{ Outcome } \\
\cline { 2 - 5 } & Discharged & Died & LAMA & Transfer out & \\
\hline MgSO $_{4}$ given & $5(19.2 \%)$ & $7(26.9 \%)$ & $6(23.1 \%)$ & $8(30.8 \%)$ & 0.033 \\
Mechanical ventilation & $16(15.4 \%)$ & $22(21.2 \%)$ & $17(16.3 \%)$ & $49(47.1 \%)$ & 0.001 \\
Neurological outcome & & & & & \\
$\quad$ Normal & $18(16.5 \%)$ & $11(10.1 \%)$ & $10(9.2 \%)$ & $70(64.2 \%)$ & $<0.001$ \\
Impaired & $0(0 \%)$ & $12(52.2 \%)$ & $7(30.4 \%)$ & $4(17.4 \%)$ & \\
\hline
\end{tabular}

$\begin{array}{lllll}\text { Pak J Med Sci September - October } 2019 & \text { Vol. } 35 & \text { No. } 5 & \text { www.pjms.org.pk } 1235\end{array}$ 
pattern of age distribution is being endorsed by many other researchers. ${ }^{1,78}$ A study done by Oyedeji et al. showed tetanus in a slightly older age group as the highest prevalence was seen in age group of $10-15$ years $(54.5 \%)$, followed by $22.7 \%$ each $>1$ month to 5 years and $>5$ to 10 years. ${ }^{9}$ In majority of researches on tetanus from all over the world there is male preponderance. We had $70 \%$ of male children affected by tetanus and a similar Male: Female ratio of 1.7: 1.0 is described in a research from Nigeria. ${ }^{10} \mathrm{~A}$ male predominance confirmed in our study is consistent with findings of many other researchers showing that male preponderance is due to the fact that male children are more prone to accidental injuries due to their adventurous nature which puts them at greater risk of injuries.,11

As far as the portal of entry is concerned trauma is identified as the major cause in many studies and regarding the site of trauma, majority of the children had injury to lower limbs or foot. In our study, there was significant history of trauma in $43 \%$ of patients but still in almost $25 \%$ no portal of entry was identified. Other causes were ear and nose pricks by unhygienic techniques $(18 \%)$ and ear discharge in $14 \%$. Similar findings are shown in a study by Junejo et al. documenting wound as a source of infection in $60.8 \%$, discharging ear $21.62 \%$, and cause remained unidentified in $2617.56 \% .{ }^{8}$ Ear infection is young children is often taken lightly but almost $33.3 \%$ of tetanus occurred through this route documented in a study by Alhaji et al. ${ }^{7} \mathrm{~A}$ study from India showed ear infection as the most common route of infection $49 \%$ followed by trauma $29 \% .{ }^{12}$

Despite enormous efforts of our health care authorities and our government the vaccination status of Pakistani children in general is not good. We found that only one third of children who presented with tetanus had received three doses of tetanus toxoid but none of the children received booster dose. A study from Pakistan showed much worse results about the vaccination status showing that none of patients was vaccinated for tetanus. ${ }^{13}$ Majority of our children were not immunized or partially immunized, which is similar to reports by other workers and a study by Oyedeji et al. showed exactly similar ratio of completely vaccination and partially or totally unvaccinated children. ${ }^{1,5,9}$ Another factor responsible for these tetanus cases is that routine EPI schedule doesn't contain any booster dose after one year of age and there is no awareness of adult immunization in Pakistan.
Regarding the lack of awareness and practices about the booster doses a study from Nigeria teaching hospital showed that none of the patients received booster dose after their first birthday. ${ }^{9}$ Quite contradictory to this fact of lack of booster doses of tetanus toxoid a study from a developing country by Tadele showed booster vaccination in $29 \%$ of the patients. ${ }^{2}$

Prolonged hospitalization averaging 3-4 weeks reported by various workers is in agreement with the three weeks amongst our patients. Mean duration of ICU stay in our study was $20 \pm 13.3$ days consistent with the finding of a study done by Animasahun in which average length of stay was 20 days. ${ }^{10}$ Prolonged length of stay in ICU of 2.5-7 weeks were for mechanical ventilator support, tracheostomy requirement for respiratory compromise or antispasmodic medications such as magnesium sulphate. ${ }^{14}$

While managing patients with tetanus, autonomic instability, nosocomial sepsis and ventilator-associated pneumonia are major issues faced in the intensive care setting. We faced autonomic instability in $56 \%$ of our patients and nosocomial infection occurred in $73.5 \%$. Magnesium sulphate has been used both in artificially ventilated patients to reduce autonomic disturbance and in non-ventilated patients to control spasms. Few studies also mentioned these two common problems in tetanus patients managed in ICU setting., 415

In our study one third of total patients required mechanical ventilator support and 19\% patients had tracheostomy. Neurological impairment although not a feature of tetanus but we encounter it in 17\% of patients requiring prolonged ventilation and resulting from brain anoxia. In a study published by Muazzam et al. $41 \%$ patients required tracheostomy, $39.9 \%$ patients did not require any respiratory support and endotracheal tube was needed in 5\%. Case fatality rate in our study was $17.4 \%$ consistent with a study Oyedeji showing mortality rate of $18 \%$. A study from nigeria showed the lowest mortality of $5.9 \%{ }^{16}$ A much higher fatality rate was observed in various researches ranging from $26 \%$ to $39 \%$ and a study from Nigeria showed case fatality rate of $61 \%$ in post neonatal tetanus. ${ }^{17}$

Strengths and Limitations: Our strength is a large sample size as most studies from all around the world had a much smaller sample. Limitation is that we did not collect the data regarding parental education level which has a significant impact on the vaccination status of the child. 


\section{CONCLUSION}

Post neonatal tetanus has remained a major public health problem with high morbidity and mortality rates especially in developing countries like ours. Tetanus is causing our children to suffer from devastating disease. Vaccination status is not satisfactory and booster doses are not taken into account. Along with trauma, ear discharge and ear or nose prick are identifiable risk factors. Ear discharge in pediatric population is an ignored entity and special attention should be given to discharging ears. To combat these issues large scale vaccination and booster doses remains promising option and health education regarding care of the wound and ear discharge is also needed.

\section{Conflicts of interest: None.}

\section{Grant Support \& Financial Disclosures: None.}

\section{REFERENCES}

1. Ide L, Uchenwa-Onyenegecha T. Post Neonatal Tetanus: 20 Years Experience as Seen at the University of Port Harcourt Teaching Hospital. BJMMR. 2016;12(2):1-5.

2. Tadele H. Clinical Profile and Outcome of Pediatrics Tetanus: The Experience of a Tertiary Hospital in Ethiopia. Ethiop J Health Sci. 2017;27(5):559-564. doi: 10.4314/ejhs.v27i5.14.

3. Narang M, Khurana A, Gomber S, Choudhary N. Epidemiological trends of tetanus from East Delhi, India: A hospital-based study. J Infect Public Health. 2014;7(2):121124. doi: 10.1016/j.jiph.2013.07.006.

4. Singhi S, Jain V, Subramanian C. Post-neonatal tetanus: issues in intensive care management. Indian J Pediatr. 2001;4(4):167-173

5. Muazzam M, Mansoor SA, Badar S, Nadeem A, Anwar B, Waseer MH, et. al. TETANUS; Still cannot be prevented, a three year retrospective study in DHQ hospital, Faisalabad. Prof Med J. 2013;20(6):1026-1034.

6. Ide Y, Eberechukwu L, Angela BN. The Socio-Economic Challenges in Post Neonatal Tetanus. Mod Econ. 2015;6:1327-1332. doi: 10.4236/me.2015.612125.

7. Alhaji MA, Akuwa RT, Mustapha MG, Ashir GM, Mava Y, Elechi HA BF. Post-neonatal tetanus in University of Maiduguri Teaching Hospital. Niger J Paediatr. 2013;40(2):154-157. doi: 10.4314/njp.v40i2,9
8. Junejo AA, Abbasi KA, Shaikh AH. A Three Year Retrospective Review of Post Neonatal Tetanus at Children Hospital, Chandka Medical College, Larkana. Pak Paediatr J. 2012;36(1):7-11.

9. Oyedeji O, Fadero F, Joel-Medewase V, Elemile P, Oyedeji A. Trends in tetanus admissions in the paediatric age group at a Nigerian teaching hospital. Trop Med Int Heal. 2012;6(12):847-853. doi: 10.3855/jidc. 2105.

10. Animasahun BA, Gbelee OH, Ogunlana AT, Njokanma OF, Odusanya O. Profile and outcome of patients with postneonatal tetanus in a tertiary centre in south west Nigeria: Any remarkable reduction in the scourge? Pan Afr Med J. 2015;21:1-10. doi: 10.11604/pamj.2015.21.254.6488.

11. Tullu MS, Deshmukh CT, Kamat JR. Experience of pediatric tetanus cases from Mumbai. Indian Pediatr. 2000;37:765-771.

12. Mondal T, Aneja S, Tyagi A, Kumar P, Sharma D. A study of childhood tetanus in post-neonatal age group in Delhi. Indian Pediatr. 1994;31(11):1369-1372.

13. Naseem F, Mahar IH, Arif F. Two years' study of Tetanus cases in a Paediatric Intensive Care Unit. Pak J Med Sci. 2016;32(3):641-645. doi: 10.12669/pjms.323.9165.

14. Wen C, Webb SC, Miles F, Wilson E. Tetanus in New Zealand children: Intensive care management of a vaccine preventable disease. J Paediatr Child Health. 2016;52(12):1070-1074. doi: 10.1111/jpc.13306.

15. Angurana SK. Jayashree M, Bansal AK. Post-neonatal Tetanus in a PICU of a Developing Economy: Intensive Care Needs, Outcome and Predictor. J Trop Pediatr. 2018;64(1):1523. doi: $10.1093 /$ tropej/fmx020.

16. Akuhwa RT, Alhaji MBM. Post-Neonatal Tetanus in Nguru, Yobe State, North-Eastern Nigeria. Niger Med Pract. 2010;57(3):1-6. doi: 10.4314/nmp.v57i3.55752.

17. Imoudu IA, Ahmad H, Yusuf MO, Makarfi HU, Umara T. A Primordial Killer Still on the Prowl : A Short Report on Paediatric Tetanus in North-Eastern Nigeria. AJMPCP. 2017;1(1):1-5.

\section{Author`s Contribution:}

NS: Conceived, designed, data collection.

AB: Statistical analysis and manuscript writing.

MF: Review, suggestions.

MS: ICU patient monitoring. 